\title{
Antithrombotic/antiplatelet therapy and colonoscopy results in patients over 50 with iron-deficiency anemia
}

\author{
Tolga Olmez, Hilmi Bozkurt, Selcuk Gulmez, Emre Aray, Zeliha Ozlem Sert, Esin Kaplan, \\ Can Ibrahim Bulut, Erdal Karakose, Erdal Polat, Mustafa Duman
}

Department of Gastrointestinal Surgery, Kartal Kosuyolu High Speciality and Training Hospital, Istanbul, Turkey

Submitted: 14 May 2019

Accepted: 12 June 2019

Arch Med Sci Civil Dis 2019; 4: e28-e33

DOI: https://doi.org/10.5114/amscd.2019.86738

Copyright (c) 2019 Termedia \& Banach

\section{Abstract}

Introduction: This study aims to evaluate the results of asymptomatic patients who have been using anticoagulant-antiaggregant (AC-AA) agents and have had colonoscopy screening due to iron-deficiency anemia (IDA). Material and methods: The data of 347 asymptomatic patients over the age of 50, who have received colonoscopy due to IDA, were reviewed retrospectively. The effects of sex and AC-AA administration on positive colonoscopy results, preneoplastic lesions and malignancy were investigated.

Results: Of 347 patients over 50 with IDA, 204 were female (58.8\%). The mean age was $63.4 \pm 8.4$. Positive colonoscopy results were observed more commonly in 69 male patients compared to 67 female patients $(p=0.004)$. Similarly, positive colonoscopy results were found to be more frequent among patients using AC-AA $(p=0.019)$. While premalignant lesions were more frequently diagnosed in male patients (23\% to $10.2 \%)$, the results were also statistically significant $(p=0.002)$. Anticoagulant administration did not contribute to the increase in preneoplastic lesion rates $(15.57 \%$ to $15.55 \%)$. Malignant pathology, which was seen in 8 male patients, was more common among male patients yet it was not statistically significant ( $p=$ 0.081). However, compared to 3 patients who did not use AC-AA, malignant pathology was seen more frequently in 9 patients who were on AC-AA and the figure was statistically significant $(p=0.009)$.

Conclusions: The AC-AA administration in asymptomatic patients over 50 with IDA who have had colonoscopy screening increases the rate of colorectal malignancy diagnosis, while it leads to no change in the rate of preneoplastic lesion detection. Nevertheless, male sex is a factor that increases the possibility of preneoplastic lesion detection.

Key words: colonoscopy, iron deficiency anemia, antithrombotic.

\section{Introduction}

Iron-deficiency anemia (IDA) is seen among adult males and postmenopausal women at the rate of $2-5 \%[1,2]$. At the same time, it has assumed epidemic levels in many developing countries and is the most common micronutrient deficiency in the world [3, 4]. In addition to micronutrient deficiency, chronic blood loss too can be among the causes of IDA [5].

Chronic gastrointestinal bleeding could be the cause of IDA among males over 50 and postmenopausal women and patients are commonly

\author{
Corresponding author: \\ Tolga Olmez MD \\ Gastrointestinal \\ Surgery Fellow \\ Kartal Kosuyolu \\ High Speciality \\ and Training Hospital \\ Denizer caddesi \\ 34865 Istanbul, Turkey \\ Phone (mobile): \\ +90 5327631058 \\ Fax: +90 2164596321 \\ E-mail: tolgaolmez@gmail. \\ com
}


referred to endoscopists for gastrointestinal system (GIS) screening $[6,7]$. Screening is performed on the upper and lower GIS to reach a differential diagnosis. IDA may arise from benign diseases in the GIS as well as from asymptomatic colorectal cancer [8].

The preventative and therapeutic use of antithrombotic (anticoagulant-antiaggregant) medication has been gradually increasing $[9,10]$. The GIS screening may be required for the patients using these agents because of anemia and bleeding [11].

Particularly the colonoscopy procedure may increase cardiovascular, neurovascular and pulmonary complications in elderly patients and those with cardiovascular disease [12-15]. With these patients, the use of anticoagulant (AC) - antiaggregant (AA) agents or temporarily discontinuing them before the procedure is of critical importance since bleeding or thromboembolic events may occur $[16,17]$.

Though it is stated that colonoscopy screenings can be safely performed while patients are on AC-AG medication due to comorbidity [18], the necessity of colonoscopy for the purpose of IDA screening for these high-risk patients is alarming in the face of possible complications of the procedure. In this study we aimed to evaluate the results of asymptomatic patients who have been using anticoagulant-antiaggregant (AC-AA) agents for therapeutic or prophylactic purposes and have had colonoscopy screening due to IDA.

\section{Material and methods}

Approval was obtained from the Ethics Committee for Human Research of the institution where the study was carried out (No. 2019.1/4-153). Later, the data of the patients who were referred to our endoscopy unit between August 2016 and July 2018 because of IDA and received colonoscopy screening were retrospectively reviewed. Patients who had been diagnosed to have IDA by internal medicine and gastroenterology units (males hemoglobin $(\mathrm{Hb})<13 \mathrm{mg} / \mathrm{dl}$, females $\mathrm{Hb}<12 \mathrm{mg} /$ $\mathrm{dl}$, mean corpuscular volume $(\mathrm{MCV})<80 \mathrm{fl}$, ferritin $<15 \mathrm{ng} / \mathrm{ml}$ iron were considered to be deficiency anemia) were referred to our unit $[2,19]$.

Patients over 18 with IDA not attributable to another cause (pica, etc.) and who did not have benign anorectal disease in their anamneses and physical examinations were included in the study.

Patients under the age of 18 , with a history of intestinal cancer or surgery or a genetic familial cancer (FAP; Lynch syndrome, etc.), patients in follow-up for colon polyps, those with chronic disease anemia (renal insufficiency, etc.), those with such GIS symptoms and findings as melena, hematochezia and abdominal ache were excluded. The condition that patients should have fecal oc- cult blood test was not stipulated because in our country patients over 50 receive at least one colonoscopy a year even if their fecal occult blood test results are negative.

Colon cleansing was performed with the standard $500 \mathrm{mg}$ sennoside (XM solution, Yenisehir Lab, Istanbul, Turkey) and $118 \mathrm{ml}$ sodium dihydrogen/disodium phosphate enema (B.T. Enema, Yenisehir Lab, Istanbul, Turkey). Due to its comorbidity, the colonoscopy procedure of certain risky patients was performed only after an anesthesia evaluation. The procedure in certain patients was performed in the operating room environment upon the recommendation of anesthetists. Before the procedure a premedication of propofol (1\%, FreseniusKabi, Istanbul, Turkey) and fentanyl citrate (0.5 mg/10 ml, VEM, Istanbul, Turkey) was administered by anesthetists. In the procedures Fujinon 530 WL4 590 WL4 (Fujinon, Willich, Germany), Olympus 160 VR (Olympus, Japan) video-colonoscopy devices and equipment were used.

Patients who had had colonoscopy due to IDA were identified through the hospital automation system, their colonoscopy results were recorded and among these patients those who used AC-AA agents at least for 3 months and the medications they used were recorded; the data in question were confirmed by calling the patients on the phone.

Data and the pathology results pertaining to those that were recorded included age (year), sex (male/female), IDA (existent/non-existent), the use of AC-AA agents (yes/no), name of medication (acetylsalicylic acid, warfarin, clopidogrel, apixaban, rivaroxaban and their combinations), normal colonoscopy results (yes/no) and the site where the positive colonoscopy result was detected (right colon; caecum, ascending, hepatic flexure, transverse $1 / 3$ proximal; left colon; transverse 2/3 distal, descending, sigmoid colon and rectum).

Patients were divided into 3 groups based on the data gathered from pathological findings: those with positive colonoscopy results, those with preneoplastic lesions and those with malignancy.

\section{Statistical analysis}

The data were uploaded in and analyzed by SPSS version 21.0 (IBM Corp.; Armonk, NY, USA). Categorical measurement was summarized in numbers and percentages and continuous measurement was summarized in mean and standard deviation figures (median and minimum-maximum when necessary). The mean figure for \pm standard deviation (SD) was calculated for age. Sex, IDA presence, use of AC-AA agents, medication used, colonoscopy findings, and results according to pathology reports were entered in frequency and percentage. While Student's t-test was used 
Table I. Patients' data in terms of age groups

\begin{tabular}{|lccc|}
\hline Parameter & $\begin{array}{c}50 \text { years and below } \\
(n=186)\end{array}$ & $\begin{array}{c}\text { Above 50 years } \\
(n=347)\end{array}$ & $P$-value \\
\hline Number of patients with positive finding in colonoscopy & $21(11.2 \%)$ & $136(39.2 \%)$ & $<0.001$ \\
\hline Premalignant lesion & $8(4.3 \%)$ & $54(15.5 \%)$ & $<0.001$ \\
\hline Malign lesion & $1(0.5 \%)$ & $12(3.4 \%)$ & 0.037 \\
\hline Number of patients on AC-AA (\%) & $23(12.3 \%)$ & $122(35.1 \%)$ & $<0.001$ \\
\hline
\end{tabular}

$A C-A A$ - anticoagulant-antiaggregant agent.

in analyses for age groups, the differences between binary groups were compared using the $\chi^{2}$ test. $P$-value $\leq 0.05$ was set to be statistically significant. Logistic regression analysis was used in values affecting colonoscopy results.

\section{Results}

In the designated time period, colonoscopy procedures were performed on 572 patients due to IDA and this figure constituted $26.3 \%$ of all the colonoscopy procedures in the same time period. Colonoscopy procedures of 39 patients were considered incomplete since the results were unclear and inadequate, leading to exclusion from the study; thus, 533 patients were included in the study with 341 (63.9\%) female and 192 male patients. The mean age was $55.8 \pm 13$ (19-92) years. Three hundred and forty-seven $(65.1 \%)$ patients were over the age of $50(p<0.001)$. At the same

Table II. Demographic data concerning patients over the age of 50

\begin{tabular}{|c|c|c|}
\hline Parameter & Value & $P$-value \\
\hline \multicolumn{3}{|l|}{ Age: } \\
\hline Mean \pm SD & $63.4 \pm 8.4$ & \\
\hline Age range & $51-92$ & \\
\hline \multicolumn{3}{|l|}{ Sex: } \\
\hline Male (\%) & $143(41.2 \%)$ & 0.001 \\
\hline Female (\%) & $204(58.8 \%)$ & \\
\hline Patients on AC-AA (\%) & $122(35.2 \%)$ & $<0.001$ \\
\hline \multicolumn{3}{|l|}{ Name of medication: } \\
\hline Acetylsalicylic acid & 62 & $<0.001$ \\
\hline Warfarin & 22 & \\
\hline Clopidogrel & 13 & \\
\hline Apixaban & 2 & \\
\hline Rivaroxaban & 1 & \\
\hline $\begin{array}{l}\text { Double-triple } \\
\text { combinations }\end{array}$ & 22 & \\
\hline
\end{tabular}

time, $39.1 \%$ of the patients over 50 were detected to have positive colonoscopy results (results that required follow-up, treatment or pathologic sampling) and correspondingly preneoplastic and malignant lesions were also observed more commonly among patients over 50. Likewise, the use of AC-AA agents was also more common among patients over 50 (Table I).

Since colorectal cancer screenings are performed after the age of 50 and for the sake of forming a more homogeneous group, the study was continued with patients over 50 . In conclusion, the data of 347 patients over 50 were analyzed.

Of 347 patients over 50 with IDA, 204 were female (58.8\%) and 143 male. The mean age was $63.4 \pm 8.4$. Demographic data of the patients are presented in Table II. The colonoscopy results of $39.2 \%$ (136 patients) of 347 patients over 50 were positive. Among these patients, the most common finding was polyp in 87 (64\%) patients and 13 (9.6\%) patients had masses. Granulomatous colitis was reported in 1 patient whose colonoscopy result revealed a mass. The pathology results of 12 patients whose colonoscopy showed masses were reported to be adenocarcinoma. While 54 patients with polyps, whose pathological sampling was conducted, were detected to have preneoplastic lesions (tubular adenoma (TA), low-grade dysplasia (LGD), high-grade dysplasia (HGD)), 33 patients were reported to have benign symptoms. Diverticular disease was observed in $33(24.3 \%)$ patients while vascular dysplasia was seen in 3 patients $(0.9 \%)$ (Table III).

Positive results in the colonoscopy were seen more frequently in 69 male patients compared to 67 females $(p=0.004)$. Similarly, positive colonoscopy was observed more commonly among patients on AC-AA agents ( $p=0.019)$.

Premalignant lesions were observed in $62 \%$ of the patients who had polypectomy surgery. The detection rate of premalignant lesions among all the colonoscopies in patients over 50 was $15.5 \%$. While premalignant lesions were statistically significantly more commonly seen in male patients, the administration of anticoagulant medication did not increase the detection rate of preneoplas- 
tic lesions (Table IV). The mean age of patients with preneoplastic lesion was 64.5 years. In the AC-AA group, the mean age was 65.6 (56-80) years while it was 64 (51-92) years in the group that was not on AC-AA. There was no difference in terms of colonic localization.

Though malignant pathology was more frequent among male patients, with 8 cases, it was not statistically significant $(p=0.081)$. However, malignant pathology was more frequent, with 9 cases among patients on AC-AA as opposed to 3 cases among the patients not on AC-AA, and this was statistically significant $(p=0.009)$ (Tables IV and $V$ ). The mean age of the patients who were detected to have malignancy was 66.7 years, the mean age of the group on AC-AA was 68.6 (58-92) years, while it was 61 (54-74) years in the group not on AC-AA.

In addition, malign pathology was found to be more frequent in the right colon (10 vs. 2) ( $p<$ 0.001). The use of acetylsalicylic acid turned out to be significantly high among patients with right colon malignancy $(p=0.011)$.

\section{Discussion}

Iron-deficiency anemia is one of the most common types of anemia [20]. This type of anemia is a common cause of referral to medical departments as it involves individuals of all ages and both sexes.

Iron-deficiency anemia related to chronic blood loss is usually asymptomatic and can be detected only when patients become symptomatic [21]. Patients included in this study were composed of those without active bleeding and GIS symptoms. That is, patients were examined by means of colonoscopy before becoming seriously symptomatic. In various studies the incidence/prevalence rate for colorectal cancer is
Table III. Colonoscopy results

\begin{tabular}{|c|c|c|}
\hline Parameter & $\begin{array}{l}\text { Number of } \\
\text { patients (\%) }\end{array}$ & $P$-value \\
\hline \multicolumn{3}{|c|}{ Positive finding in colonoscopy: } \\
\hline Yes & $136(39.2)$ & $<0.001$ \\
\hline No & 211 & \\
\hline \multicolumn{3}{|l|}{ Disease: } \\
\hline Polyp & $87(64)$ & $<0.001$ \\
\hline Diverticula & $33(24.3)$ & \\
\hline Mass & $13(9.6)$ & \\
\hline Vascular dysplasia & $3(0.9)$ & \\
\hline \multicolumn{3}{|l|}{ Segment: } \\
\hline Left colon & $93(68.4)$ & $<0.001$ \\
\hline Right colon & 43 & \\
\hline \multicolumn{3}{|l|}{ Pathology: } \\
\hline Edema-inflammation & 18 & $<0.001$ \\
\hline Hyperplastic polyp & 15 & \\
\hline Adenoma (tubular, etc.) & 25 & \\
\hline LGD & 27 & \\
\hline HGD & 2 & \\
\hline Malignancy & 12 & \\
\hline
\end{tabular}

cited as 5-10\% [22-26]. The present study includes no data pertaining to the use of anticoagulant medication. As opposed to the studies mentioned above, the reason why $3.4 \%$ of the patients over 50 with IDA had colorectal cancer may be attributed to the fact that the patients included in our study had received colonoscopy before becoming seriously symptomatic.

Table IV. Statistical analysis of colonoscopy results in terms of AC-AA use

\begin{tabular}{|lccccc|}
\hline Variable & Using AC-AA $(n=122)$ & Not using AC-AA $(n=225)$ & OR & $95 \%$ Cl & $P$-value \\
\hline $\begin{array}{l}\text { Positive finding in } \\
\text { colonoscopy }\end{array}$ & $58(47.5 \%)$ & $78(34.6 \%)$ & 1.70 & $1.09-2.67$ & 0.019 \\
\hline Precancerous lesion & $19(15.57 \%)$ & $35(15.55 \%)$ & 1.00 & $0.54-1.83$ & 0.99 \\
\hline Malignancy & $9(7.3 \%)$ & $3(1.3 \%)$ & 5.89 & $1.56-22.19$ & 0.009 \\
\hline
\end{tabular}

$A C$ - $A A$ - anticoagulant-antiaggregant agent, $O R$ - odds ratio, $C l$ - confidence interval.

Table V. Statistical analysis of colonoscopy results in terms of sex

\begin{tabular}{|c|c|c|c|c|c|}
\hline Variable & Male sex $(n=143)$ & Female sex $(n=204)$ & OR & $95 \% \mathrm{Cl}$ & $P$-value \\
\hline $\begin{array}{l}\text { Positive finding in } \\
\text { colonoscopy }\end{array}$ & $69(48.2 \%)$ & $67(32.8 \%)$ & 1.90 & $1.22-2.95$ & 0.004 \\
\hline Preneoplastic lesion & $33(23 \%)$ & $21(10.2 \%)$ & 2.63 & $1.44-4.73$ & 0.002 \\
\hline Malignancy & $8(5.5 \%)$ & $4(1.9 \%)$ & 2.95 & $0.87-10$ & 0.81 \\
\hline
\end{tabular}

$A C$ - $A A$ - anticoagulant-antiaggregant agent, $O R$-odds ratio, $C l$ - confidence interval. 
In the management of IDA, upper GIS endoscopy and colonoscopy are highly important in terms of diagnosis for postmenopausal women and male patients. Patients without any salient GIS symptoms in this group are likely to have positive results in colonoscopy. Colonic screening is necessary for premenopausal women below the age of 50 if they have colonic symptoms and a strong familial history (2 first degree relatives or 1 first degree relative under the age of 50) [27] or if IDA persists despite iron supplementation. Especially cancerous and preneoplastic lesions in the colon may lead only to IDA without presenting any other symptoms.

When hyperplastic polyps are high in number and large in size, the risk of colorectal cancer development increases [28]. Since there was no patient who did not fit into hyperplastic polyposis syndrome in our study, we considered hyperplastic polyps as benign and did not include these patients in the precancerous group.

Preneoplastic colorectal lesions were observed in $15.5 \%$ of patients over the age of 50 . While the annual risk of malign transformation in adenomatous polyps is $0.25 \%$, it is tubulovillous or villous in character and the risk increases to as high as $50 \%$ as the severity of dysplasia intensifies [29]. According to Kishida et al., colorectal polyps of $\geq 1 \mathrm{~cm}$ are more likely to lead to iron deficiency [30]. Small polyps may not account for the cause of IDA; however, thanks to a polypectomy being performed, the risk that colorectal cancer could develop in the future can be diminished.

A randomized controlled trial established that fecal occult blood test and colonoscopy performed when the test turns out to be positive decreased mortality rates related to colonic cancer [31].

Positivity in the fecal occult blood test in patients who use antithrombotic medication in creases the need for colonoscopy screening [32]. Colonoscopy results may reveal malign lesions or adenomatous polyps, as well as benign symptoms that could lead to hemorrhage. Likewise, in our study the number of patients with positive colonoscopic findings and malignancy was found to be significantly higher in the AC-AA group. Only preneoplastic lesions did not present any difference between the two groups.

A prospective study by James et al. dealing with risk factors of IDA in GIS cancers established the presence of colonic cancer in $6.3 \%$ of the patients irrespective of age and that gastrointestinal system cancers were more common among patients over 50 [26]. The same study demonstrated that the use of AC-AA agents did not have significant effects on the development of cancers of the gastrointestinal system. In our study, which evaluated GIS cancers, colorectal cancer incidence was much higher in patients over 50 and the use of AC-AA agents increased the frequency of colorectal cancer in the same group. In addition, it was observed that the use of aspirin was higher among those who were diagnosed with colonic cancer.

Because our hospital where this study was carried out is at the same time a cardiac diseases center, a considerable number of patients were on AC-AA agents. With these patients on AC-AA agents due to comorbidity and for whom interventional procedures such as colonoscopy posed risks, it was necessary to review the necessity of the procedure once again. Colonoscopic examination became inevitable for patients who had a history of critical cardiac disease such as heart transplant, low ejection fraction and pulmonary hypertension when their IDA could not be attributed to any cause. Of 347 patients over 50, who formed the basis of the study, 122 patients had already been using AC-AA agents regularly for these reasons or for prophylaxis.

As Johnson et al. stated in a study with a large patient population, non-gastrointestinal side effects after colonoscopy were significantly higher among patients who were using anti-thrombotic medication than those who were not [33]. We did not examine the side effects of colonoscopy in our study. However, precancerous and malign lesions were detected in $22.8 \%$ of the group on AC-AA agents; after taking the necessary precautions this rate can be seen as an adequate reason for disregarding possible side effects.

The primary limitation of this study is that it was conducted retrospectively. Since data such as patients' comorbidity and post-colonoscopy complications could not be obtained in their entirety from the hospital automation system, a reliable analysis could not be conducted. Therefore, a prospective study can be devised to develop projects that would decrease morbidity and mortality rates arising from the colonoscopy procedure among this group of risky patients.

In conclusion, colonoscopy screening is an important step in the examination of asymptomatic patients over the age of 50 with IDA. The use of AC-AA, which is common in this group of patients, increases the detection rate of colorectal malignancy, yet does not lead to any changes in the rate of preneoplastic lesions. Nevertheless, male sex is a factor that increases the possibility of preneoplastic lesion detection Therefore, doctors should not refrain from performing colonoscopy screening of patients on AC-AA due to comorbidity and old age; the procedure should be carried out by taking all the necessary precautions.

\section{Conflict of interest}

The authors declare no conflict of interest. 


\section{References}

1. Guralnik JM, Eisenstaedt RS, Ferrucci L, Klein HG, Woodman RC. Prevalence of anemia in persons 65 in the United States: evidence for a high rate of unexplainedanemia. Blood 2004; 104: 2263-8.

2. World Health Organization. Iron Deficiency Anaemia Assessment, Prevention and Control: A Guide for Programme Managers. Geneva: World Health Organization 2001.

3. Chandyo RK, Henjum S, Ulak M, et al. The prevalence of anemia and iron deficiency is more common in breastfed infants than their mothers in Bhaktapur, Nepal. Eur J Clin Nutr 2016; 70: 456-62.

4. Abu-Ouf NM, Jan MM. The impact of maternal iron deficiency and iron deficiency anemia on child'shealth. Saudi Med J 2015; 36: 146-9.

5. Lopez A, Cacoub P, Macdougall IC, Peyrin-Biroulet L. Iron deficiency anaemia. Lancet 2016; 387: 907-16.

6. Andrews P. A. Disorders of iron metabolism. N Engl J Med 2000; 342: 1293-4.

7. McIntyre AS, Long RG. Prospective survey of investigations in outpatients referred with iron deficiency anemia. Gut 1993; 34: 1102-7.

8. Goodman D, Irvin TT. Delay in the diagnosis and prognosis of carcinoma of the right colon. Br J Surg 1993; 80: 1327-9.

9. Antman EM, Wiviott SD, Murphy SA, et al. Early and late benefits of prasugrel in patients with acute coronary syndromes undergoing percutaneous coronary intervention: a TRITON-TIMI (Trial to Assess Improvement in Therapeutic Outcomesby Optimizing Platelet InhibitioN with Prasugrel-Thrombolysis In Myocardial Infarction) analysis. J Am Coll Cardiol 2008; 51: 2028-33.

10. Anderson JL, Adams CD, Antman EM, et al. ACC/AHA 2007 guidelines for the management of patients with unstable angina/non-ST-elevation myocardial infarction: a report of the American College of Cardiology/ American Heart Association Task Force on Practice Guidelines (Writing Committee to Revisethe 2002 Guidelines for the Management of Patients With Unstable Angina/Non-ST-Elevation Myocardial Infarction) developed in collaboration with the American College of Emergency Physicians, the Society for Cardiovascular Angiography and Interventions, and of Thoracic Surgeons endorsed by the American Association of Cardiovascular and Pulmonary Rehabilitation and the Society for Academic Emergency Medicine. J Am Coll Cardiol 2007; 50: e1-157.

11. Pirmohamed M, James S, Meakin S, et al. Adverse drug reactions as cause of admission to hospital: prospective analysis of 18,820 patients. BMJ 2004; 329: 15-9.

12. Rutter CM, Johnson E, Miglioretti DL, Mandelson MT, Inadomi J, Buist DS. Adverse events after screening and follow up colonoscopy. Cancer Causes Control 2012; 23: 289-96.

13. Fox JP, Burkardt DD, Ranasinghe I, Gross CP. Hospital-based acute care after outpatient colonoscopy: implications for quality measurement in the ambulatory setting. Med Care 2014; 52: 801-8.

14. Tran AH, Man Ngor EW, Wu BU. Surveillance colonoscopy in elderly patients: a retrospective cohort study. JAMA Intern Med 2014; 174: 1675-82.

15. Hawn MT, Graham LA, Richman JS, Itani KM, Henderson WG, Maddox TM. Risk of major adverse cardiac events following noncardiac surgery in patients with coronary stents. JAMA 2013; 310: 1462-72.
16. Acosta RD, Abraham NS, Chandrasekhara V, et al. The management of antithrombotic agents for patients undergoing GI endoscopy. Gastrointest Endosc 2016; 83: 3-16.

17. Becker RC, Scheiman J, Dauerman HL, et al. Management of platelet-directed pharmacotherapy in patients with atherosclerotic coronary artery disease undergoing elective endoscopic gastrointestinal procedures. Am J Gastroenterol 2009; 104: 2903-17.

18. Veitch AM, Vanbiervliet G, Gershlick AH, et al. Endoscopy in patients on antiplatelet or anticoagulant therapy, including direct oral anticoagulants: British Society of Gastroenterology (BSG) and European Society of Gastrointestinal Endoscopy (ESGE) guidelines. Gut 2016; 65: 374-89.

19. Camaschella C. Iron-deficiency anemia. N Eng J Med 2015; 372: 1832-43.

20. Vucelic D, Nenadic B, Pesko P, et al. Iron deficiency anemia and its importance in gastroenterology clinical practise. Acta Chirur Iugoslav 2007; 54: 91-105.

21. Cook JD, Skikne BS: iron deficiency: definition and diagnosis. J Intern Med 1989; 226: 349-55.

22. Kepczyk T, Kadakia SC. Prospective evaluation of gastrointestinal tract in patients with iron-deficiency anemia. Dig Dis Sci 1995; 40: 1283-9.

23. Rockey DC, Cello JP. Evaluation of the gastro-intestinal tract in patients with iron-deficiency anemia. N Engl J Med 1993; 329: 1691-5.

24. Cook IJ, Pavli P, Riley JW, Goulston KJ, Dent OF. Gastrointestinal investigation of iron deficiency anaemia. BMJ 1986; 292: 1380-2.

25. Hardwick RH, Armstrong CP. Synchronous upper and lower gastrointestinal endoscopy is an effective method of investigating iron-deficiency anaemia. $\mathrm{Br} J$ Surg 1997; 84: 1725-8.

26. James MW, Chen CM, Goddard WP, Scott BB, Goddard AF. Risk factors for gastrointestinal malignancy in patients with iron-deficiency anaemia. Eur J Gastroenterol Hepatol 2005; 17: 1197-203.

27. Cairns SR, Scolefield JH, Steele RJ, et al. Guidelines for colorectal cancer screening in high risk groups (update from 2002). Gut 2010; 59: 666e90.

28. Boparai KS, Mathus-Vliegen EM, Koornstra JJ, et al. Increased colorectal cancer risk during follow-up in patients with hyperplastic polyposis syndrome: a multicenter cohort study. Gut 2010; 59: 1098-100.

29. NCCN Clinical Guidelines in Oncolgy. Colorectal Cancer screening, 2013.

30. Kishida T, Shinozawa I, Tanaka S, Hoshino T. Significance of serum iron and ferritin in patients with colorectal adenomas. Scand I Gastroenterol 1997; 32: 233-7.

31. Mandel JS, Bond JH, Church TR, et al. Reducing mortality from colorectal cancer by screening for fecal occult blood. Minnesota Colon Cancer Control Study. N Engl J Med 1993; 328: 1365-71.

32. Zuckerman GR, Prakash C, Askin MP, Lewis BS. AGA technical review on the evaluation and management of occult and obscure gastrointestinal bleeding. Gastroenterology 2000; 118: 201-21.

33. Johnson DA, Lieberman D, Inadomi JM, Ladabaum U, Becker RC, Gross SA. Increased post-procedural nongastrointestinal adverse events after outpatient colonoscopy in high-risk patients. Clin Gastroenterol Hepatol 2017; 15: 883-91. 